\title{
EXPERIMENTAL AND NUMERICAL STUDIES OF FATIGUE PROPERTIES OF CARBON/GLASS FIBER/EPOXY HYBRID COMPOSITES ENHANCED WITH NANO $\mathrm{TiO}_{2}$ POWDER
}

\author{
Mustafa Baqir HUNAIN ${ }^{1}$, Basim A. ABASS ${ }^{1}$, Jaafar Musa AKHUDAIR ${ }^{2}$ \\ ${ }^{1}$ University of Babylon, Faculty of Engineering, Mechanical Engineering Department, Babylon, Iraq \\ dr_m_hunain@yahoo.com \\ ${ }^{2}$ M. Sc. Student, University of Babylon, Faculty of Engineering, Mechanical Engineering Department, \\ Babylon, Iraq
}

\begin{abstract}
The present work deals with the fatigue behavior of hybrid nanocomposites consisting epoxy strengthen by unidirectional carbon fibres, and/or woven roving glass fiber and $\mathrm{TiO}_{2}$ nanofillers. For this purpose, nanocomposite material was manufactured by mixing $\mathrm{TiO}_{2}$ nanoparticles with the epoxy using an ultrasonic mixer to insure complete dispersion of such particles in the base material. Different particle concentrations ( 1 , 3 , and 5) \% wt. of $\mathrm{TiO}_{2}$ nanoparticles have been added to the epoxy. Different types of hybrid nano composite materials were manufactured by adding three layers of carbon fibers and/or woven roving glass fiber to the prepared epoxy nanocomposite materials with a constant weight fraction of $30 \%$. The laminated hybrid nanocomposite materials were then prepared using hand lay-up technique using a vacuum device. For experimental purposes tensile and fatigue test specimens have been manufactured according to ASTM-D3039 and ASTM D 3479/D 3479M-96, respectively, while ANSYS19 program was used to analyze the fatigue behavior of such materials numerically. Tensile tests were carried out at room temperature while fatigue tests has been carried out at constant stress ratio $(\mathrm{R}=-1)$. Scanning electron microscope (SEM) was used to identify the underlying mechanisms for fatigue failure and the progressive of damage growth. For each test, three specimens were tested and the average magnitude for each property was taken. The results obtained indicated that the hybrid nanocomposite $\left(\mathrm{EP}+\mathrm{C} / \mathrm{C} / \mathrm{C}+3 \% \mathrm{TiO}_{2}\right)$ has the highest fatigue limit and tensile strength in comparison with the other tested material, while the SEM results showed that the composite failed by a brittle way. It has been also generally observed that the addition of $\left(\mathrm{TiO}_{2}\right)$ nanoparticles has a positive effect on the fatigue behaviour of the such materials.
\end{abstract}

Keywords: Hybrid Nano-composite materials, Fatigue, Mechanical properties.

\section{INTRODUCTION}

Structures are normally subjected to vibrations and other changing loads which degrade stressful materials. Fatigue is a major cause of the failure of structural components. Mechanical behavior of composites under fatigue loading seems to be affected by fiber breakage, matrix cracking, interfiber fracture, and delamination between the layers. Different types of polymers such as epoxy, polyester, and vinylesters were used as a base for the composite materials [1] [2]. Many studies have confirmed that the incorporation of the small volume fraction of nanofibers as a filler in the polymer led to improve several fatigue properties. Grimmer and Dharan [3] show that the addition of small volume fractions of multi-walled carbon nanotubes [MWCNTs] to the epoxy matrix /glass fibers, resulted in a significant increase in high cycle fatigue life. Khan, et al [4] stated that combination of nano clay into CFRP composites can be improve the composite's mechanical properties in static loading as well as the fatigue life for a cyclic load and the mechanical residual properties after a given cyclic fatigue period. Pinto et al [5] displayed that the fatigue crack propagation resistance of the epoxy resin can be improved by the addition of $\mathrm{TiO}_{2}$ nanoparticles. Wetzel et al [6] exhibit that adding $\mathrm{Al}_{2} \mathrm{O}_{3}$ nanoparticles to the epoxy improves its fatigue crack propagation resistance. It has been shown that the crack in dynamically loaded nanocomposites propagated at lower rates than in neat epoxy. Ajaj et al [7] observed that the existence of silica nanoparticles in the epoxy polymer decreases the brittleness of epoxy resin and improving the maximum fatigue stress, fatigue life, and surface roughness of the composite. Khan, et al [8] investigated the influence of nano clay addition on fatigue behavior of carbon fiberreinforced polymers (CFRPs). The obtained results showed that combination of nano clay into CFRP composites not only increases the composite's mechanical properties in static loading as well as the fatigue behaviour for a given cyclic load level and the mechanical properties after a given cyclic fatigue period. Borrego, et al [9] studied the fatigue behavior of nano clay and multiwalled carbon nanotubes composites. It has been observed that the 
fatigue ratio in tension-tension loading rises with the addition of nano clay and multi-walled carbon nanotubes, proposing that both types of nanoparticles can act as retards to the fatigue crack propagation. Ansari, et al [10] studied the effects of fiber volume fraction, fiber orientation, fiber type, etc. on the fatigue life behavior of fiber-reinforced polymer composites. It has been concluded that the frequency of fatigue increases and then decreases with the increase of the fraction of the fiber volume to a certain amount. C. Capela et al. [11], investigated the fatigue life of Epoxy-based composite strengthen with carbon fiber with various volume fractions within 5-20\% and $500 \mu \mathrm{m}$ length. The results indicated an enhancement in the fatigue, tensile strength, and stiffness attendant to the fiber volume fraction growing up to $17.5 \%$ by $140 \%$, $52 \%$, and $400 \%$, respectively but then, the mechanical properties were slightly decreased. Amore and Grassia [12] Studied the response of carbon/epoxy composite when exposed to constant amplitude cyclic loadings to determine static strength, fatigue limit, and residual strength.. It has been noticed that the model captures the important features of the composite's response, including the hierarchical damage into particular insights development. Lee et al. [13] studied the effect of the fiber direction with three various angles $\left(0^{\circ}\right.$, $45^{\circ}$, and $90^{\circ}$ ) on the high cycle fatigue behavior of glass fiber with $30 \mathrm{wt} \%$ implanted in Polyamide 6,6 . The results exposed that the glass fiber with $0^{\circ}$ direction has the highest fatigue life strength for all the testing conditions, and the failure has occurred due to microcracks generation, debonding, and voids at the fiber ends. Bondy et al. [14] studied the influence of the direction of the fiber on the fatigue life of nylon 6,6 reinforced with 40 percent long carbon fiber directed at three different flow angles $\left(0^{\circ}, 45^{\circ}\right.$, and $\left.90^{\circ}\right)$. The results showed that the rise in the fiber flow angle affected a decrease in the degree of fatigue stress. Mustafa B. Hunain et al, [15] investigated experimentally the effects of activated carbon powder, with various weight fraction ratios of $(0,5,10,15,20,25,30,35$ and 40) \% wt. , with epoxy resin on tensile properties, The results showed that the tensile strength magnitude increased with increasing AC content up to $15 \%$ wt., then it decreased at $40 \%$ wt. Basim A. Abass et al [16] investigated the mechanical properties of a hybrid epoxy composite strengthened by $\mathrm{TiO}_{2}$ nano powder, glass fibbers and unidirectional carbon fiber. Different weight percentages of $\mathrm{TiO}_{2}$ nano-powder was dispersed in epoxy using sonication. The results show that the addition of $\mathrm{TiO} 2$ nanoparticles at up to $3 \% \mathrm{wt}$ enhances the mechanical strength of such material. Ali S. Al-Turaihi et al [17] deals with the effect of volume fractions $(0,10$, and $20 \%)$ on the fatigue life of unsaturated polyester matrix reinforced with E-glass chopped fiber experimentally and numerically. The results show that the tensile strength and elastic modulus of such composite is increased when the volume fraction increased from $0 \%$ to $20 \%$, while the fatigue strength of composite reinforced with $20 \%$ of volume fraction increased by about $48 \%$ compared with that pure polyester. The numerical part using ANSYS/16 workbench software shows good agreement with the experimental part with maximum max difference of 7\%. Mustafa B. Hunain et al [18] examined the tensile strength of laminated polymer matrix carbon fiber composites for different stacking sequence. The results showed that the sequence of the fibre layer is very important in case of use unidirectional fibres.

It is clear from the above literatures that the tensile and fatigue and behaviour of laminated composite material consists of epoxy resin strengthened with unidirectional carbon and/or woven roving glass fibres with and without nanotitanium dioxide have been a little studied, which is the essential purpose of the present work.

In this work, the effect of adding $\mathrm{TiO}_{2}$ nanoparticles with various weight percentages $(1,3$, and 5). on tensile and fatigue properties of epoxy reinforced with three laminates of carbon and/or woven roving glass fibres with $30 \%$ wt. was examined and discussed in detail experimentally and numerically.

\section{EXPERIMENTAL WORK}

\subsection{Materials}

Materials used for experiments of the present work include the epoxy resin used as a matrix of the nano hybrid composite materials. Epoxy type Quickmast 105 produced by "Don Construction Products (DCP) company", with suitable hardener was used in the present work. Mixing ratio is 1.47:4, solidifying time 40 minutes at $35^{\circ} \mathrm{C}$, density $1.1 \mathrm{~g} / \mathrm{cm}^{3}$, and mixing viscosity 1.0 poise at $35^{\circ} \mathrm{C}$ [19]. $\mathrm{TiO}_{2}$ nanoparticles produced by "MTI Corporation" with surface area per unit mass $210 \pm$ $10 \mathrm{~m}^{2} / \mathrm{g}$, average particle size of $50 \mathrm{~nm}$, a density of $0.25 \mathrm{~g} / \mathrm{cm}^{3}$, and purity greater or equal to $99.9 \%$. Unidirectional carbon fiber fabric delivered by "Sika Wrap-300 Company, Switzerland" with density $1.81 \mathrm{gm} / \mathrm{cm}^{3}$, Young modulus of elasticity 230GPa and Poisson's ratio of 0.21 [20]. Woven Roving glass fibers (GF) in the form of bidirectional fabric delivered by interweaving direct roving Fabrication Process "china" having a density of $2 \mathrm{gm} / \mathrm{cm}^{3}$, Young's modulus of elasticity of $72.53 \mathrm{GPa}$ and Poisson's ratio of 0.22 [21].

\subsection{Nanocomposite materials preparation}

The nanocomposite material was manufactured by adding different amount of $\mathrm{TiO}_{2}$ nanoparticles $(1,3$, and $5 \%$ wt.) to the epoxy resin. The epoxy resin was firstly diluted by using 2 parts of acetone solvent to 10 parts of epoxy and stirred manually for $5 \mathrm{~min}$ [22]. The $\mathrm{TiO}_{2}$ nanoparticles with specified particle concentration was then added to the epoxy and mixed using homogenizer vibrator 
"Ultrasonic Homogenizer FS-1200N". The mixture was subjected to high speed for 10 minutes in instinct designs of $20 \mathrm{~s}$ on and $10 \mathrm{~s}$ off; in order to break down the agglomerating bodies and create they fully dispersed in the liquid medium. Then, the mixture was mixed under ambient conditions using a magnetic hotplate stirrer "Labtech Co. LTD" at a high power for duration $30 \mathrm{~min}$. to confirm the evaporation of acetone. The hardener with recommended ratio $(1.47: 4)$ was then added to the mixture and all components were mixed at room temperature $\left(25^{\circ} \mathrm{C}\right)$. Reinforcing fibres and liquid matrix resin layers are added sequentially to fabricate laminated sheets using hand lay-up technique using suitable glass mould that has dimensions of $(250 \times 250 \times 4) \mathrm{mm}^{3}$ [23]. Finally, the manufactured lamina subjected to low vacuum at 30 psi for 24 hours in order to eliminate the trapped air formed as a consequence of the reaction between the components. The laminated composite was left to dry at ambient temperature for 48 hours and then the samples were left for 3 hours in an oven at $70{ }^{\circ} \mathrm{C}$ in order to achieve a sufficient curing. This procedure is essential for finishing polymerization, releasing stresses convinced during the manufacturing process, and completing sheets hardening [20].

\subsection{Fabrication of the samples}

The sheets for each hybrid nanocomposite material were then used to prepare the fatigue and tensile testing samples according to the standard of each test using CNC lathe machine "Suda ST1212 CNC router".

\subsection{Experimental Testing Procedure}

\subsubsection{Tensile test}

Tensile tests for " $\mathrm{EP}+\mathrm{C} / \mathrm{C} / \mathrm{C}$ ", " $\mathrm{EP}+\mathrm{C} / \mathrm{G} / \mathrm{C}$ ", "EP+G/C/G", and "EP+G/G/G" as well as that hybridized with $3 \% \mathrm{TiO}_{2}$ have been performed according to the ASTM-D3039 standard [24]. A universal tensile test machine with maximum load of (5KN) "LARYEE-50 KN" was used to carry out such tests. The load was applied with speed of (2 $\mathrm{mm} / \mathrm{min}$ ) at ambient temperature until the specimen's failure [25]. Young's modulus (E), ultimate tensile strength, and percentage of elongation at the break point are the main results of such test. Each test was duplicated three times for each specimen and the average magnitude were adopted.

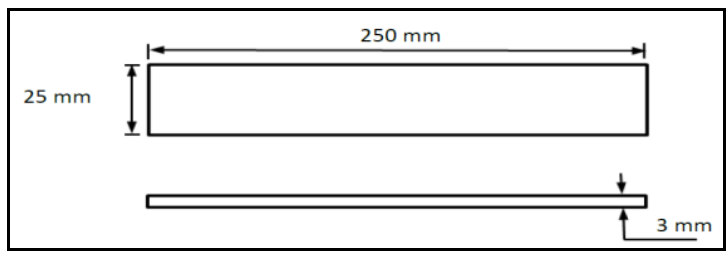

Fig. 1. Dimensions of tensile specimen according to the (ASTM D3039).

\subsubsection{Fatigue test}

Fatigue test specimens were fabricated according to "ASTM D 3479/D 3479M-96", standard test method for the fatigue of epoxy composite materials [26]. A flat plate test specimens to satisfy the machine test section with the dimensions shown in figure 1 [27] have been prepared. Fatigue tests were performed using "AVERY fatigue testing machine type 7305" which allow the application of cyclic reversed bending loading with cycling rate of $1400 \mathrm{rpm}$ with or without an initial static load.

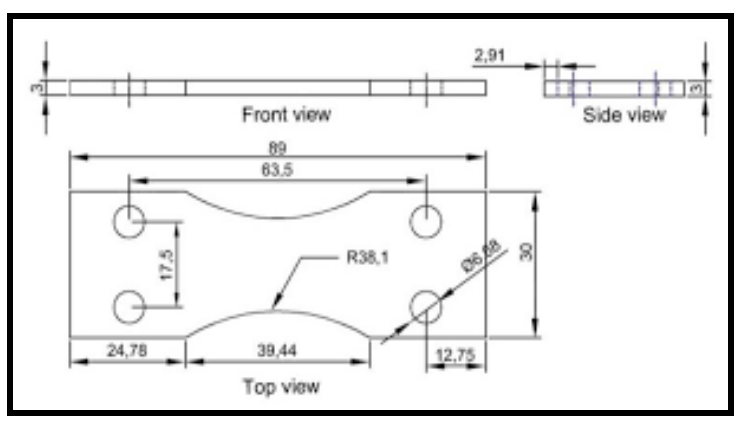

Fig. 2. Fatigue test specimen with dimensions in $\mathrm{mm}[26]$.

Grips are given for the bend test where the load is applied at one end of the specimen by an fluctuating spindle driven by means of a double eccentric attachment, crank, and connecting rod. The eccentric attachment is adaptable to give the essential range of bending angle. The applied stress is calculated from the deflection angle and the applied moment. The cyclic bending stresses were tension-compression stresses, so the machine was adjusted at a stress ratio $\mathrm{R}=-1$. Some of the tested fatigue specimens can be shown in figure 3 .

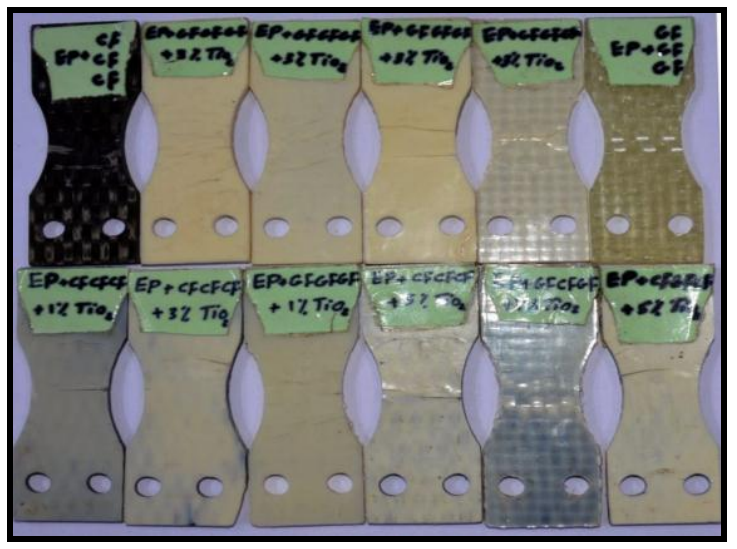

Fig. 3. Fatigue test specimen after testing.

\subsubsection{Scanning electron microscope test (SEM)}

Test specimens were cut and examined at the fracture surface using the Scanning Electron Microscope (SEM) model "VEGA3-TESCAN" shown in figure 3. The SEM was employed to determine the morphology of composite polymer specimens fabricated in this work. Specimen of small sizes $(10 \mathrm{~mm} \times 5 \mathrm{~mm})$ was employed for 
analysis at fracture plane. To get strong electrical conductivity all specimens were coated with gold by sputtering and the secondary electron images were recorded [28].

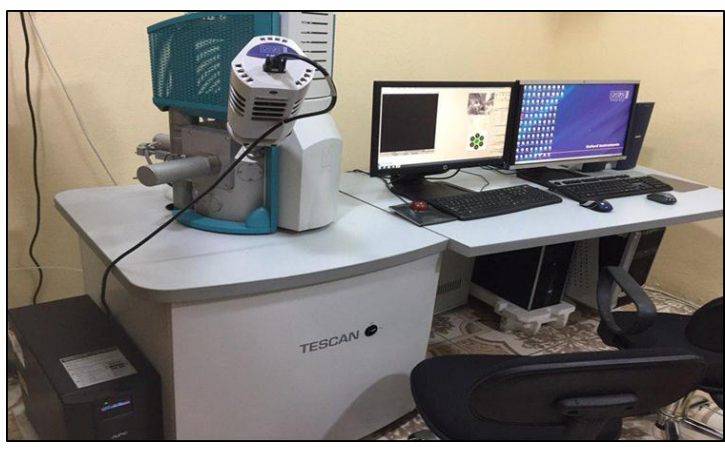

Fig. 4. Scanning electron microscope (SEM).

\section{NUMERICAL ANALYSIS}

A mathematical model for the fatigue of hybrid nanocomposite material was created using ANSYS 19 program. The fatigue specimen described previously was created using solid work program. Then the model was discretized using solid 185 structural element with total number of elements and nodes 6768 and 35579 respectively as can be shown in figure 5 (a). The main inputs to the program are Yong's modulus of elasticity, poisons ratio and density while the main output is the fatigue strength of the material. The main boundary conditions are fixed support was applied on one side while the applied load (displacement) is applied on the other side as shown in figure 5 (b).

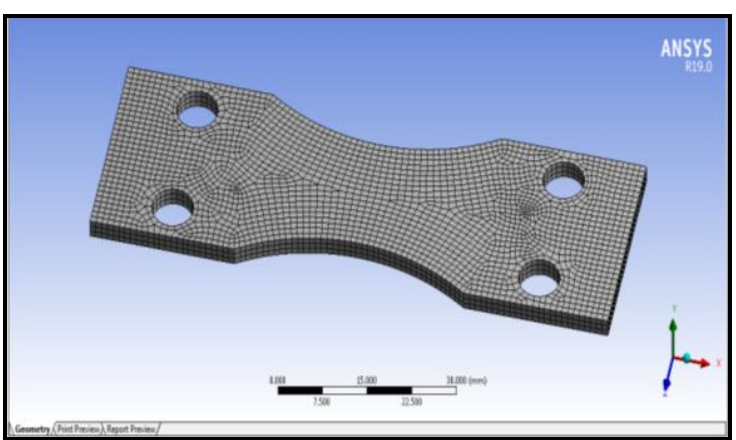

(a) Mesh generation.

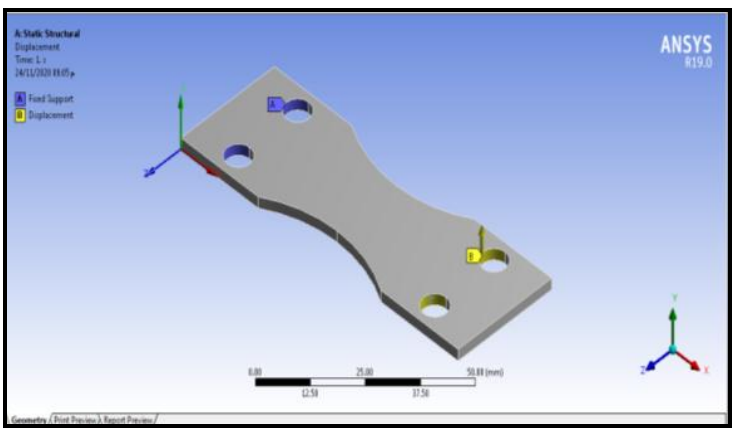

(b) Boundary conditions.

Fig. 5. Mesh generation and boundary conditions for fatigue analysis.

\section{RESULTS AND DISCUSSION}

\subsection{Tensile modulus.}

The tensile modulus of different materials studied in the present work has been obtained from the stress strain curves shown in figure 5 (a-d).

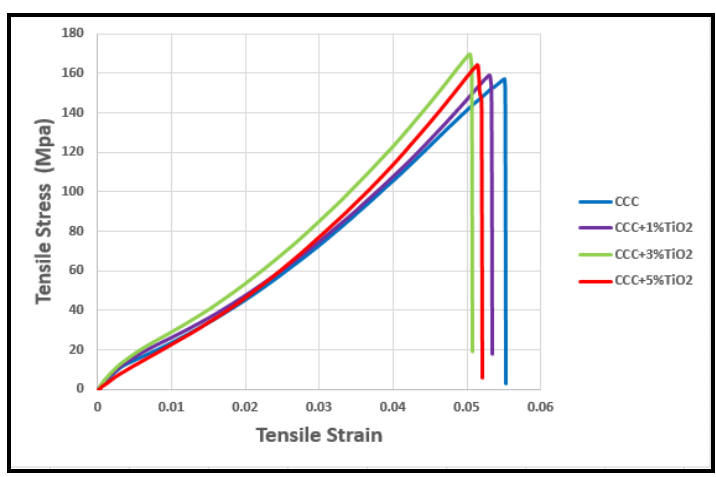

(a) $\mathrm{EP}+\mathrm{CCC}$ fibers +wt. $\%$ of $\mathrm{TiO}_{2}$ nanoparticles.

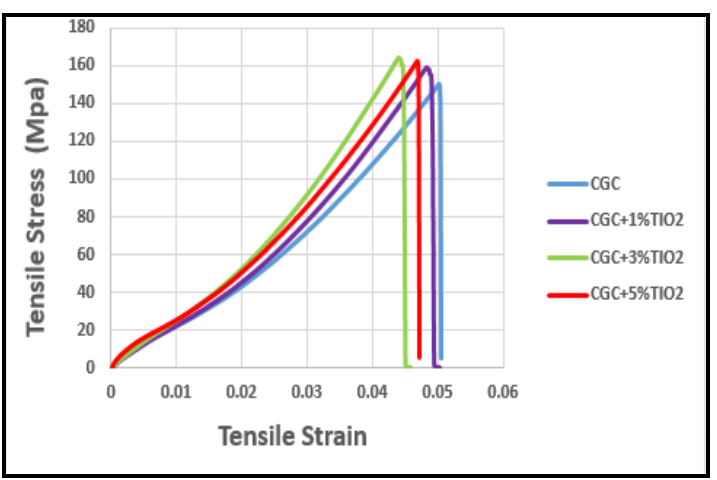

(b) $\mathrm{EP}+\mathrm{CGC}+$ wt. $\%$ of $\mathrm{TiO}_{2}$ nanoparticles.

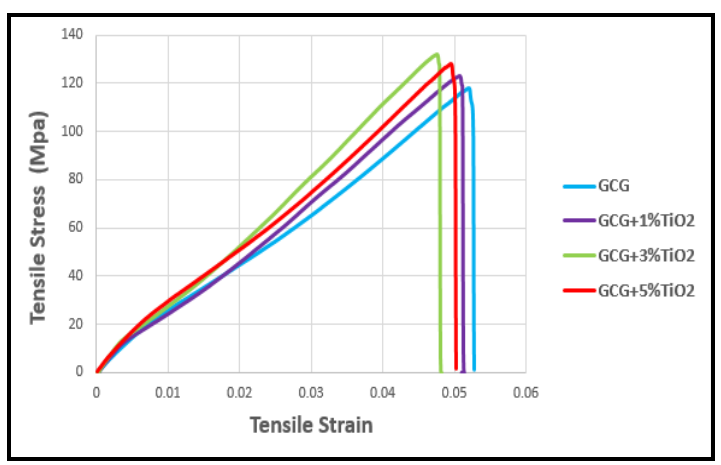

(c) $\mathrm{EP}+\mathrm{GCG}+\mathrm{wt} . \%$ of $\mathrm{TiO}_{2}$ nanoparticles.

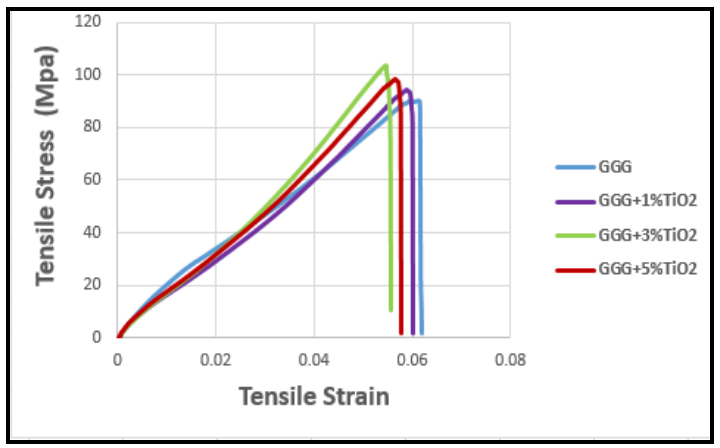

(d) EP+GGG +wt.\% of $\mathrm{TiO}_{2}$ nanoparticles.

Fig. 5. Stress-strain curves of different hybrid nanomaterials. 
The variation of tensile modulus for the composite and hybrid nanocomposite material samples with various weight fractions of $\mathrm{TiO}_{2}$ and different stacking arrangement of the fibers are presented in figure 6. It can be noticed from this figure that the hybrid nanocomposite material with $3 \% \mathrm{TiO}_{2}$ has the highest tensile modulus comparison with the composite and other tested hybrid nanocomposite materials. The percentage increase in tensile modulus hybrid nanocomposite materials with $3 \%$ wt $\mathrm{TiO}_{2}$ in comparison with other studied composite materials can be shown in table 1.

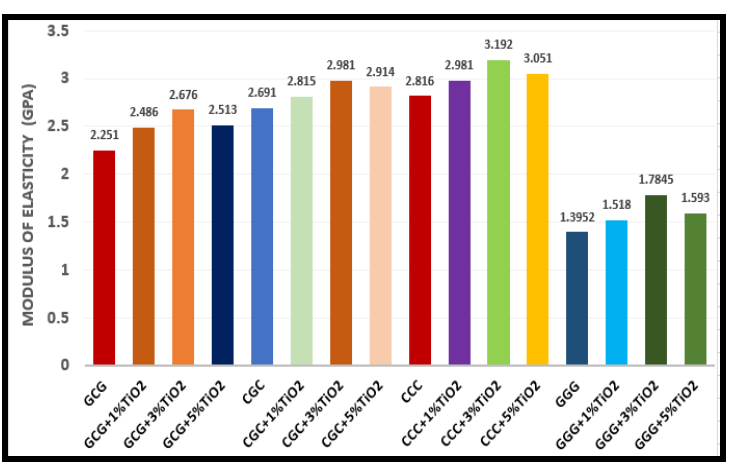

Fig. 6. Modulus of elasticity for different composite and hybrid nanocomposite materials.

Table 1. Percentage increase in Young's modulus of elasticity for hybrid nanocomposite materials.

\begin{tabular}{|l|l|l|l|l|l|}
\hline No. & $\begin{array}{c}\text { Composite } \\
\text { Material }\end{array}$ & E GPa & $\begin{array}{l}\text { Hybrid nano } \\
\text { composite material }\end{array}$ & $\begin{array}{l}\text { E } \\
\text { GPa }\end{array}$ & \%increase \\
\hline 1. & EP+GCG & 2.251 & EP+GCG $3 \% \mathrm{TiO}_{2}$ & 2.676 & 18.8 \\
\hline 2. & EP+CGC & 2.691 & EP+CGC+3\%TiO 2 & 2.981 & 10.7 \\
\hline 3. & EP+CCC & 2.816 & $\mathrm{EP}+\mathrm{CCC}+3 \% \mathrm{TiO}_{2}$ & 3.192 & 13.3 \\
\hline 4. & $\mathrm{EP}+\mathrm{GGG}$ & 1.3952 & $\mathrm{EP}+\mathrm{GGG}+3 \% \mathrm{TiO}_{2}$ & 1.7845 & 27.9 \\
\hline
\end{tabular}

Figure 7 comparison for the Yong modulus of elasticity results obtained from different composite materials studied in this work when it hybridized with different amount of $\mathrm{TiO}_{2}$ nanoparticles. It can be seen from this figure that the composite material composed of epoxy reinforced with three layers of carbon fibers and $3 \% \quad \mathrm{TiO}_{2}$ has the maximum Young's modulus (3.192MPa).

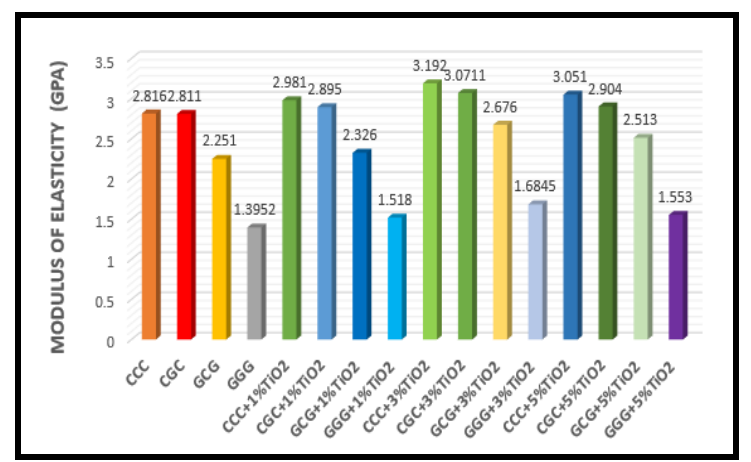

Fig. 7. Comparison Modulus of elasticity for different hybrid composite materials.

\subsection{Fatigue test results.}

\subsubsection{Experimental results}

Fatigue test was carried out for all the types of the prepared laminated composite materials. Nine specimens were tested for each type of hybrid nano composite materials under different applied moments. The results have been graphically presented in the form of $\mathrm{S}-\mathrm{N}$ curves. The $\mathrm{S}-\mathrm{N}$ curves for different hybrid nanocomposite materials with different $\mathrm{TiO}_{2}$ nanoparticles addition can be shown in figures 8-11. The results presented in these figures and that summarized in table 2 for the maximum stress to failure and the total number cycles to failure show that the laminated composite material with three layup of GGG is the more affected material by the addition of $3 \% \mathrm{TiO}_{2}$ than the other tested in the present work. The maximum percentage increase in stress to failure for $\mathrm{GGG}+3$ $\% \mathrm{wt} \mathrm{TiO}_{2}$ has been calculated and found to be $30 \%$. In general, the addition of $\mathrm{TiO}_{2}$ to the composite material with percentage up to $3 \%$ wt enhances the fatigue strength of the hybrid nanocomposite material. This can be attributed to the greater surface area of the nanoparticles which allow good adhesion between the material components and higher resistance to the crack propagation. The addition of the nanoparticles by weight percentage greater than $3 \%$ may lead to the agglomeration of such particles and decreases the fatigue strength of the material in this case. These findings supported by that obtained in references [5] and [29].

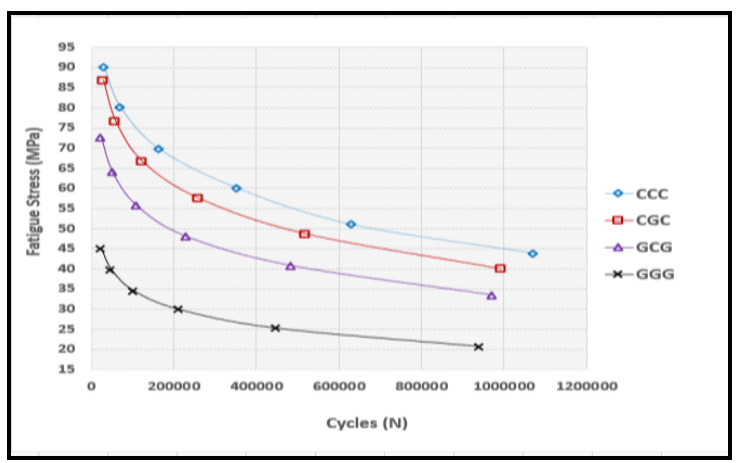

Fig. 8. S-N Curve of EP resin reinforced with 3 ply of different fibers without (TiO2) nanoparticles.

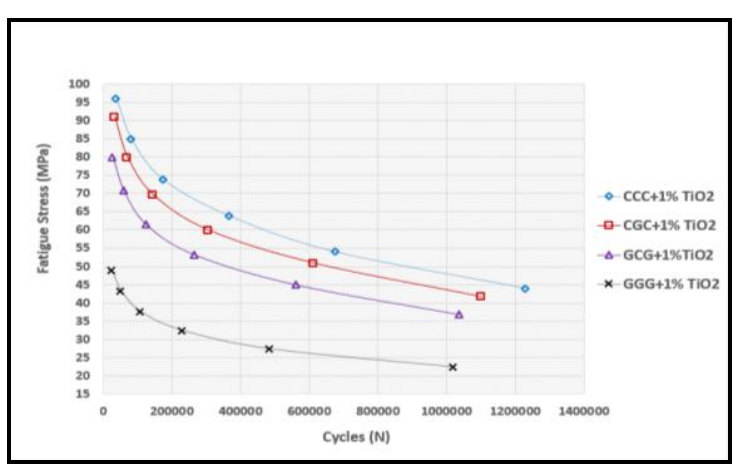

Fig. 9. S-N Curve of EP resin reinforced with (3ply) of different fibers and $\left(1 \%\right.$ wt. $\left.\mathrm{TiO}_{2}\right)$ nanoparticles. 


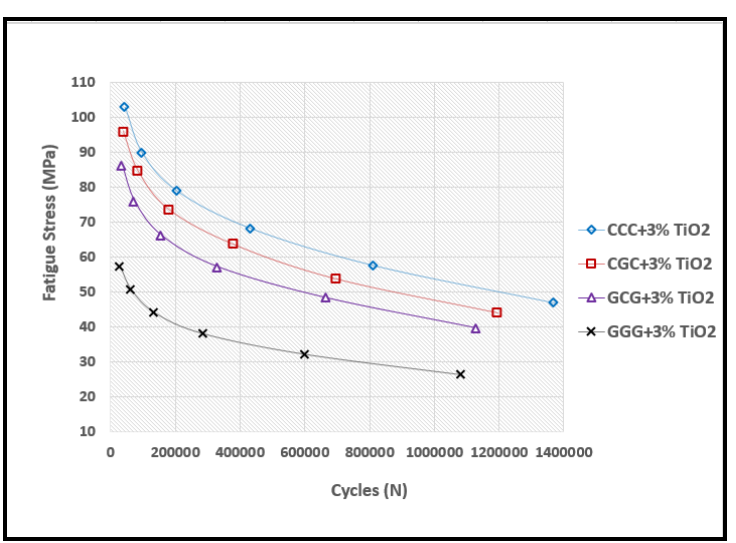

Fig. 10. S-N Curve of EP resin reinforced with (3ply) of different fibers and (3\% wt. $\mathrm{TiO}_{2}$ ) nanoparticles.

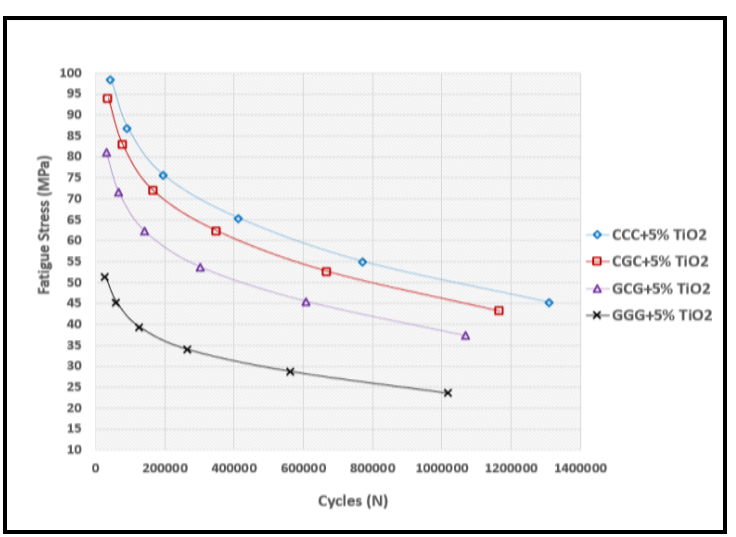

Fig. 11. S-N Curve of EP resin reinforced with (3ply) of different fibers and (5\%wt. $\mathrm{TiO}_{2}$ ) nanoparticles.

Table 2. The effect of $\mathrm{TiO}_{2}$ addition on the stress to failure of different hybrid nanocomposite materials.

\begin{tabular}{|c|c|c|c|c|c|}
\hline No. & Material & $\begin{array}{l}\% \mathrm{TiO}_{2} \\
\text { addition }\end{array}$ & $\begin{array}{c}\text { Stress to } \\
\text { failuer(MPa) }\end{array}$ & $\begin{array}{l}\text { Number of cycles to } \\
\text { failuer }\end{array}$ & $\begin{array}{c}\text { \%increase in } \\
\text { stress to failuer }\end{array}$ \\
\hline 1. & $\mathrm{CCC}$ & $\begin{array}{l}0 \\
1 \\
3 \\
5\end{array}$ & $\begin{array}{l}44 \\
45 \\
48 \\
47\end{array}$ & $\begin{array}{l}1,060,000 \\
1,240,000 \\
1,380,000 \\
1,310,000\end{array}$ & $\begin{array}{c}2 \\
9 \\
6.8\end{array}$ \\
\hline 2. & CGC & $\begin{array}{l}0 \\
1 \\
3 \\
5 \\
\end{array}$ & $\begin{array}{l}40 \\
42 \\
44 \\
43 \\
\end{array}$ & $\begin{array}{l}1,000,000 \\
1,100,000 \\
1,200,000 \\
1,180,000\end{array}$ & $\begin{array}{c}5 \\
10 \\
7.5\end{array}$ \\
\hline 3. & GCG & $\begin{array}{l}0 \\
1 \\
3 \\
5 \\
\end{array}$ & $\begin{array}{l}33 \\
37 \\
39 \\
38 \\
\end{array}$ & $\begin{array}{c}980000 \\
1,050,000 \\
1,120,000 \\
1,060,000\end{array}$ & $\begin{array}{l}12 \\
18 \\
15 \\
\end{array}$ \\
\hline 4. & GGG & $\begin{array}{l}0 \\
1 \\
3 \\
5\end{array}$ & $\begin{array}{l}20 \\
23 \\
26 \\
24\end{array}$ & $\begin{array}{c}950000 \\
1,020,000 \\
1,100,000 \\
1,020,000\end{array}$ & $\begin{array}{l}15 \\
30 \\
20\end{array}$ \\
\hline
\end{tabular}

The data presented in figures 8-11 have been correlated using Basquin's equation of the powerlaw to give the equations presented in table 3 . It can observe from this table that the obtained data are well correlated since the coefficients of determination $\mathrm{R}^{2}$ are high enough to ensure accurate fitness of the data. This result is in agreement with the reference [30].

The effect of $\mathrm{TiO}_{2}$ addition by $(1 \%, 3 \%$ and $5 \%$ ) to the each of three lamia of different composite materials can be shown in figures 12-15.
Table 3. S-N Equations of fatigue data.

\begin{tabular}{|c|l|c|c|}
\hline \multirow{2}{*}{ NO. } & \multicolumn{1}{|c|}{ Materials } & \multicolumn{2}{c|}{3 Layers } \\
\cline { 3 - 4 } & & S-N Equation & $\mathrm{R}^{2}$ \\
\hline $\mathrm{l}$ & $\mathrm{EP} / \mathrm{C} / \mathrm{C} / \mathrm{C}$ & $\sigma=226.99 N^{-0.1315}$ & 0.9984 \\
\hline 2 & $\mathrm{EP} / \mathrm{C} / \mathrm{C}+1 \% \mathrm{TiO}_{2}$ & $\sigma=254.94 N^{-0.1499}$ & 0.9991 \\
\hline 3 & $\mathrm{EP} / \mathrm{C} / \mathrm{C} / \mathrm{C}+3 \% \mathrm{TiO}_{2}$ & $\sigma=276.77 N^{-0.1616}$ & 0.9975 \\
\hline 4 & $\mathrm{EP} / \mathrm{C} / \mathrm{C} / \mathrm{C}+5 \% \mathrm{TiO}_{2}$ & $\sigma=264.33 N^{-0.1547}$ & 0.9985 \\
\hline 5 & $\mathrm{EP} / \mathrm{G} / \mathrm{C}$ & $\sigma=219.32 N^{-0.1299}$ & 0.9996 \\
\hline 6 & $\mathrm{EP} / \mathrm{C} / \mathrm{G} / \mathrm{C}+1 \% \mathrm{TiO}_{2}$ & $\sigma=234.43 N^{-0.1382}$ & 0.9993 \\
\hline 7 & $\mathrm{EP} / \mathrm{C} / \mathrm{G} / \mathrm{C}+3 \% \mathrm{TiO}_{2}$ & $\sigma=256.67 N^{-0.1510}$ & 0.9984 \\
\hline 8 & $\mathrm{EP} / \mathrm{C} / \mathrm{G} / \mathrm{C}+5 \% \mathrm{TiO}_{2}$ & $\sigma=247.65 N^{-0.1438}$ & 0.999 \\
\hline 9 & $\mathrm{EP} / \mathrm{G} / \mathrm{C} / \mathrm{G}$ & $\sigma=179.62 N^{-1063}$ & 0.999 \\
\hline 10 & $\mathrm{EP} / \mathrm{G} / \mathrm{C} / \mathrm{G}+1 \% \mathrm{TiO}_{2}$ & $\sigma=201.83 N^{-0.1189}$ & 0.9992 \\
\hline 11 & $\mathrm{EP} / \mathrm{G} / \mathrm{C} / \mathrm{G}+3 \% \mathrm{TiO}_{2}$ & $\sigma=224.84 N^{-0.1322}$ & 0.9987 \\
\hline 12 & $\mathrm{EP} / \mathrm{G} / \mathrm{C} / \mathrm{G}+5 \% \mathrm{TiO}_{2}$ & $\sigma=209.27 N^{-0.1234}$ & 0.9992 \\
\hline 13 & $\mathrm{EP} / \mathrm{G} / \mathrm{G} / \mathrm{G}$ & $\sigma=110.12 N^{-0.0652}$ & 0.9989 \\
\hline 14 & $\mathrm{EP} / \mathrm{G} / \mathrm{G} / \mathrm{G}+1 \% \mathrm{TiO}_{2}$ & $\sigma=120.67 N^{-0.0711}$ & 0.9989 \\
\hline 15 & $\mathrm{EP} / \mathrm{G} / \mathrm{G} / \mathrm{G}+3 \% \mathrm{TiO}_{2}$ & $\sigma=146.05 N^{-0.0859}$ & 0.9993 \\
\hline 16 & $\mathrm{EP} / \mathrm{G} / \mathrm{G} / \mathrm{G}+5 \% \mathrm{TiO}_{2}$ & $\sigma=130.05 N^{-0.0768}$ & 0.9991 \\
\hline
\end{tabular}

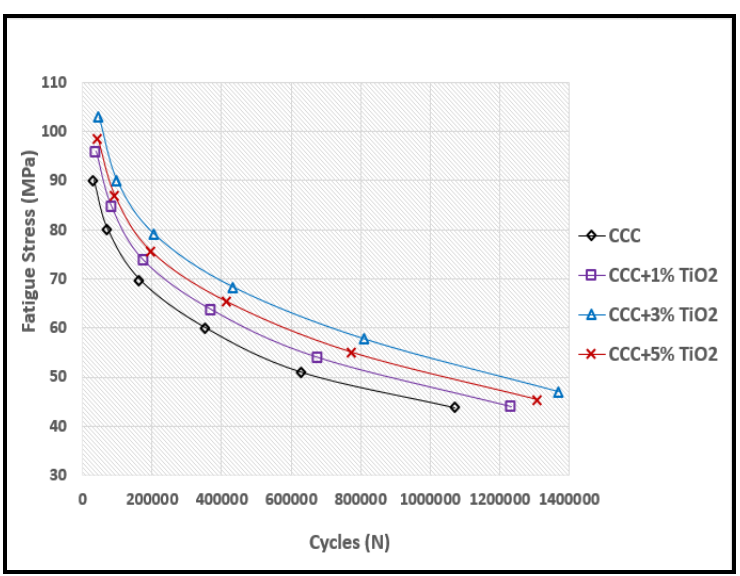

Fig. 12. S-N Curve of EP resin reinforced with 3 plys of carbon fibres and $\mathrm{TiO}_{2}$ nanoparticles.

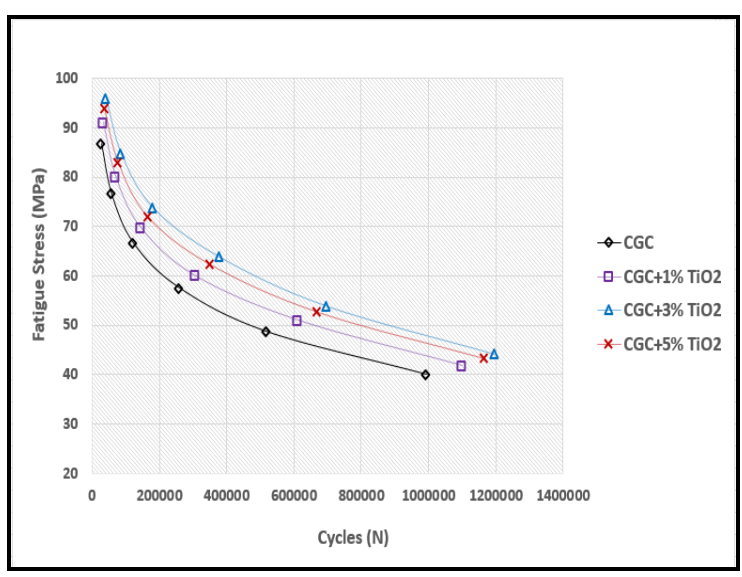

Fig. 13. S-N Curve of EP resin reinforced with 3plys of CGC fibres and $\mathrm{TiO}_{2}$ nanoparticles.

These figures obviously show that the composite material of 3plays of glass fiber has the highest enhancement in fatigue strength (30\%) when it was hybridized with $3 \%$ wt of $\mathrm{TiO}_{2}$ nanoparticles. It can also be shown that the hybrid nanocomposite with three plays of carbon fibers and $3 \% \mathrm{TiO}_{2}$ has the highest fatigue strength (48 $\mathrm{MPa}$ ) for about 1380000 cycles. 


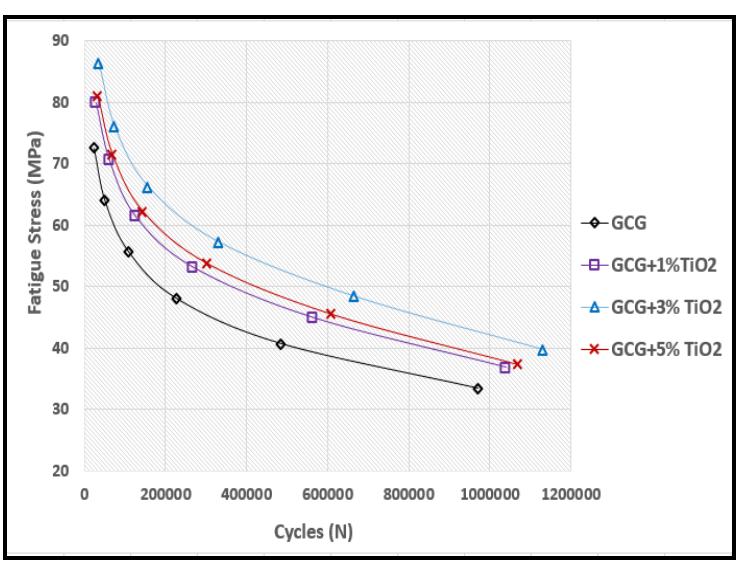

Fig. 14. S-N Curve of EP resin reinforced with 3 plys of GCG fibers and $\mathrm{TiO}_{2}$ nanoparticle.

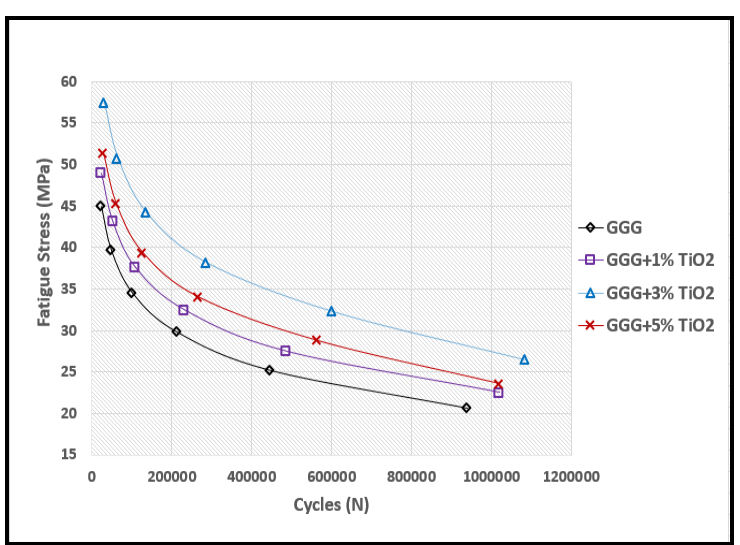

Figure 15. S-N Curve of EP resin reinforced with 3plys of GGG fibres and $\mathrm{TiO}_{2}$ nanoparticles.

\subsubsection{Numerical Results}

Numerical model was built using ANSYS 19.0 software. This model was validated by comparing the $\mathrm{S}-\mathrm{N}$ curve for $\left.\left[\mathrm{EP}+\mathrm{C} / \mathrm{C} / \mathrm{C}+3 \% \mathrm{TiO}_{2}\right)\right]$ obtained experimentally with that obtained numerically as can be shown in figure 16. The maximum percentage error between results was calculated and found to be $5 \%$ as can be shown in table 4 . This confirms the good agreement between the numerical and experimental results.

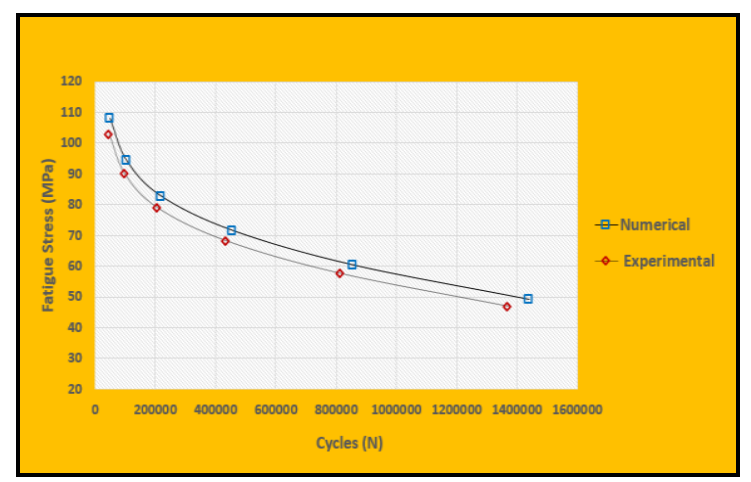

Fig. 16. Validation of the mathematical model $\mathrm{S}-\mathrm{N}$ curve for $\left.\left[\mathrm{EP}+\mathrm{C} / \mathrm{C} / \mathrm{C}+3 \% \mathrm{TiO}_{2}\right)\right]$.
All the experimental correlated formulas presented in table 3 have been obtained numerically as shown in table 4 . The fatigue limit for each studied nano hybrid composite material has been calculated numerically and compared to that obtained experimentally. The maximum percentage of error between the values of the fatigue limit was calculated and found to be $5 \%$. These numerical correlations can be used to estimate the fatigue limit of the hybrid nanocomposite material with confidence.

Table 4. Numerical and Experimental equations of S$\mathrm{N}$ Curves of higher fatigue bending load of composite materials.

\begin{tabular}{|c|c|c|c|c|}
\hline \multirow{2}{*}{\begin{tabular}{|l|}
$\begin{array}{l}\text { Type of } \\
\text { material }\end{array}$ \\
$\mathrm{EP}+\mathrm{C} / \mathrm{C} / \mathrm{C}$ \\
\end{tabular}} & S-N Equati & rical or Experimental & \multirow{2}{*}{$\begin{array}{c}\begin{array}{c}\text { Fatigue } \\
\text { limit } \\
(\mathrm{MPa})\end{array} \\
45.99\end{array}$} & \multirow{2}{*}{$\begin{array}{c}\begin{array}{c}\text { Percent- } \\
\text { deference } \\
\%\end{array} \\
5\end{array}$} \\
\hline & Num & $\sigma=240.36 N^{-0.1393}$ & & \\
\hline & Exp & $\sigma=226.99 N^{-0.1315}$ & 43.7 & \\
\hline \multirow[t]{2}{*}{$\mathrm{EP}+\mathrm{C} / \mathrm{C} / \mathrm{C}+1 \% \mathrm{TiO}_{2}$} & Num & $\sigma=268.47 N^{-0.1574}$ & 46.2 & \multirow[t]{2}{*}{4.7} \\
\hline & Exp & $\sigma=254.94 N^{-0.1499}$ & 44 & \\
\hline \multirow[t]{2}{*}{$\mathrm{EP}+\mathrm{C} / \mathrm{C} / \mathrm{C}+3 \% \mathrm{TiO}_{2}$} & Num & $\sigma=291.45 N^{-0.1697}$ & 49.25 & \multirow[t]{2}{*}{4.5} \\
\hline & Exp & $\sigma=276.77 N^{-0.1616}$ & 47 & \\
\hline \multirow[t]{2}{*}{$\mathrm{EP}+\mathrm{C} / \mathrm{C} / \mathrm{C}+5 \% \mathrm{TiO}_{2}$} & Num & $\sigma=278.33 N^{-0.1625}$ & 47.535 & \multirow[t]{2}{*}{4.7} \\
\hline & Exp & $\sigma=264.33 N^{-0.1547}$ & 45.3 & \\
\hline
\end{tabular}

\subsection{Results of Scanning Electronic Microscope (SEM)}

The scanning electronic microscope was used to study the morphological properties of the failed specimens under fully reversed fluctuating bending fatigue for hybrid nanocomposite material reinforced with three layers of carbon fiber and $\mathrm{TiO}_{2}$ nanoparticles with different particle concentrations as can be shown in figure 17 (a-h). This figure shows the main modes of fatigue fracture for different types of hybrid nanocomposite materials. It is clear that the main modes of failure for this material is the fiber fracture, delamination and fiber pullout. Formation of transverse matrix cracks can be also seen from these figures. This can be attributed to the presence of higher stress concentration followed by de-bonding of the fiber matrix and induced localized ply delamination. The matrix cracks and plies delamination expand and trigger bundles as the fatigue cycling continues (at 900 to loading direction) to split and fracture, setting the stage for final fracture.

\section{CONCLUSIONS}

Numerical and experimental investigations of the fatigue properties of epoxy resin strengthened by unidirectional carbon fibbers, woven roving glass and Titanium dioxide with different weight fractions have been implemented in the present work. The following are the main conclusion remarks:

1. Increasing the weight fraction of $\mathrm{TiO}_{2}$ nanoparticles up to $3 \%$ enhances the mechanical 
and fatigue properties of the manufactured composite and hybrid nanocomposite.

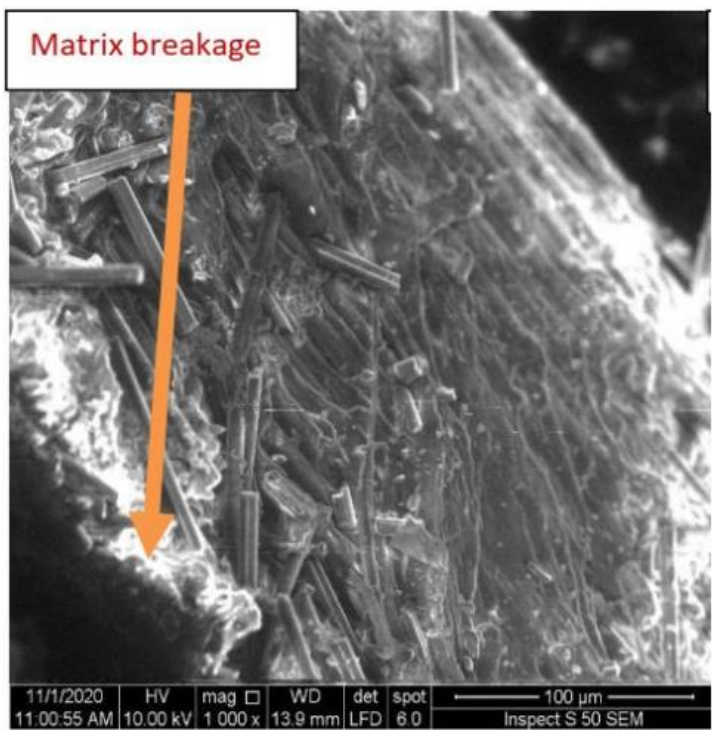

(a) $[\mathrm{EP}+\mathrm{C} / \mathrm{C} / \mathrm{C}]$

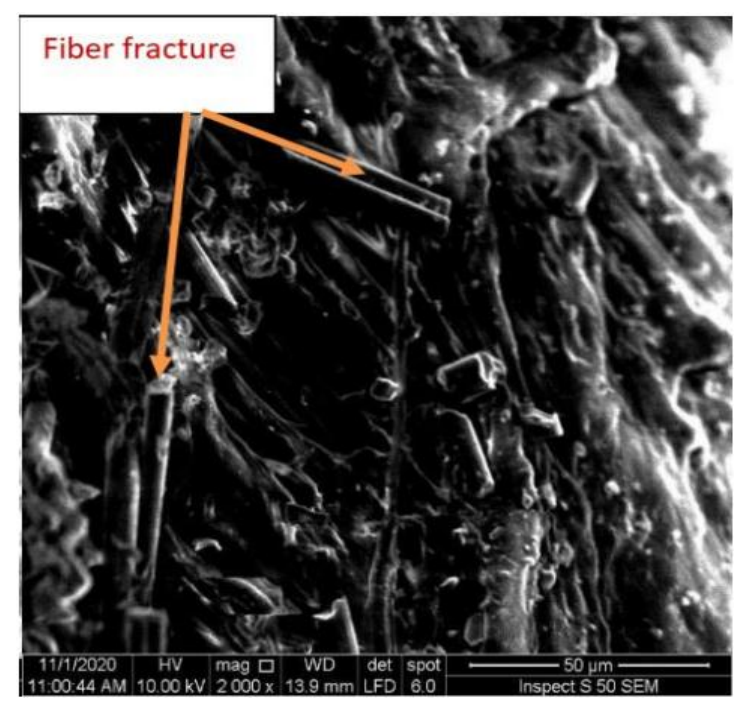

(b) $[\mathrm{EP}+\mathrm{C} / \mathrm{C} / \mathrm{C}]$

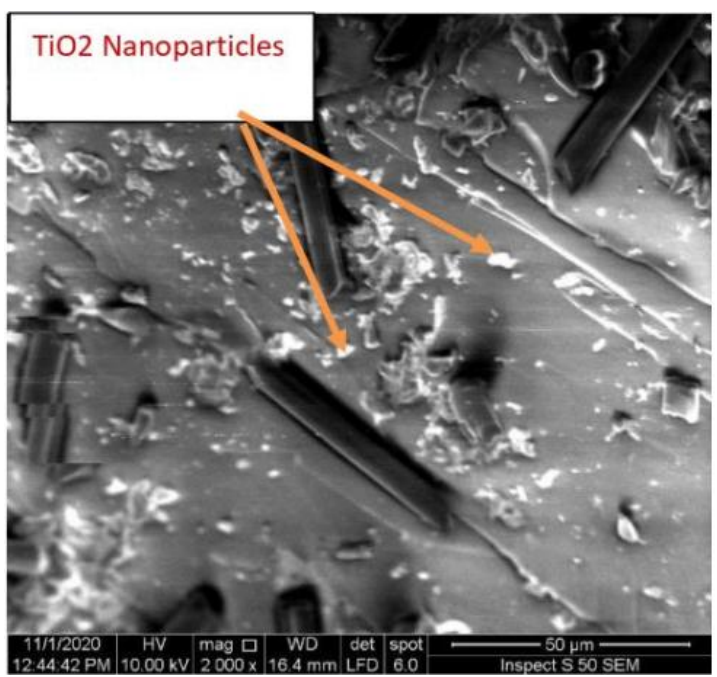

(c) $[\mathrm{EP}+\mathrm{C} / \mathrm{C} / \mathrm{C}+1 \%]$

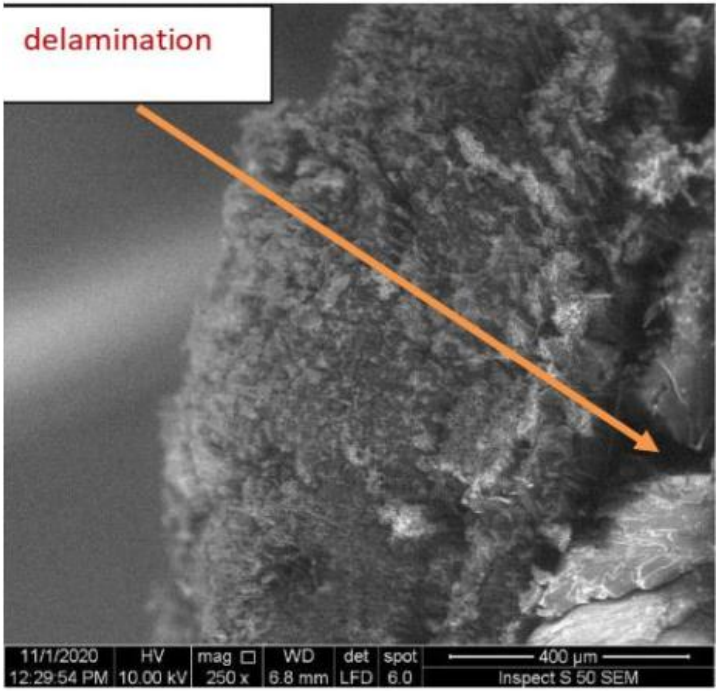

(d) $[\mathrm{EP}+\mathrm{C} / \mathrm{C} / \mathrm{C}+1 \%]$

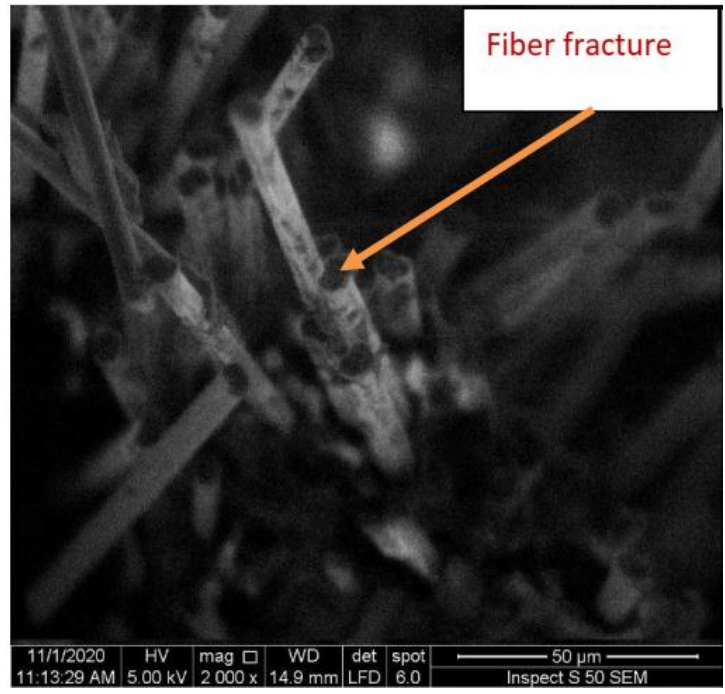

(e) $[\mathrm{EP}+\mathrm{C} / \mathrm{C} / \mathrm{C}+3 \%]$

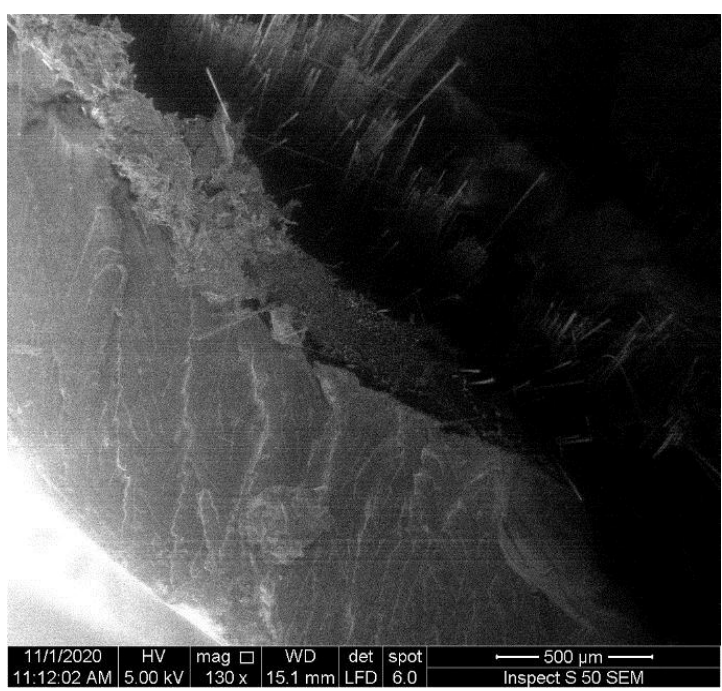

(f) $[\mathrm{EP}+\mathrm{C} / \mathrm{C} / \mathrm{C}+3 \%]$ 


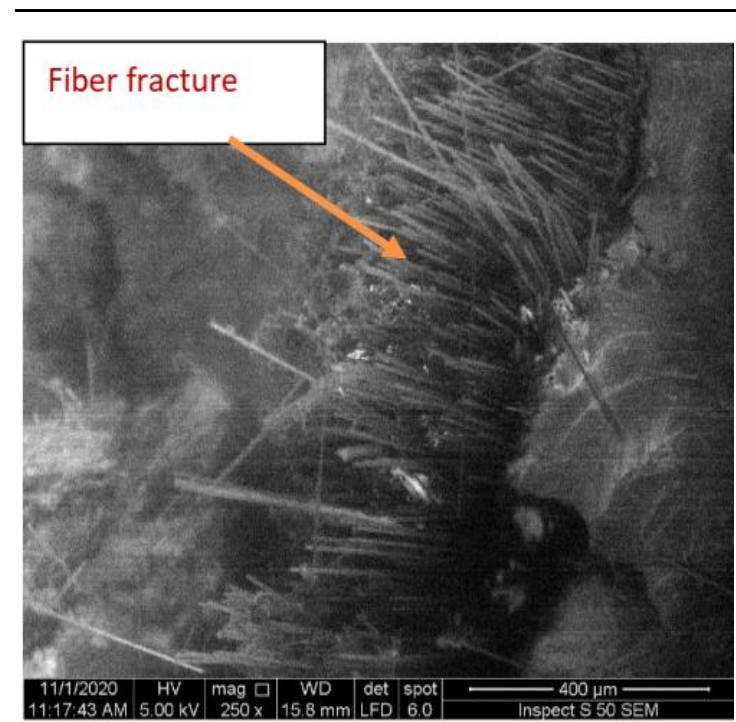

(g) $[\mathrm{EP}+\mathrm{C} / \mathrm{C} / \mathrm{C}+5 \%]$

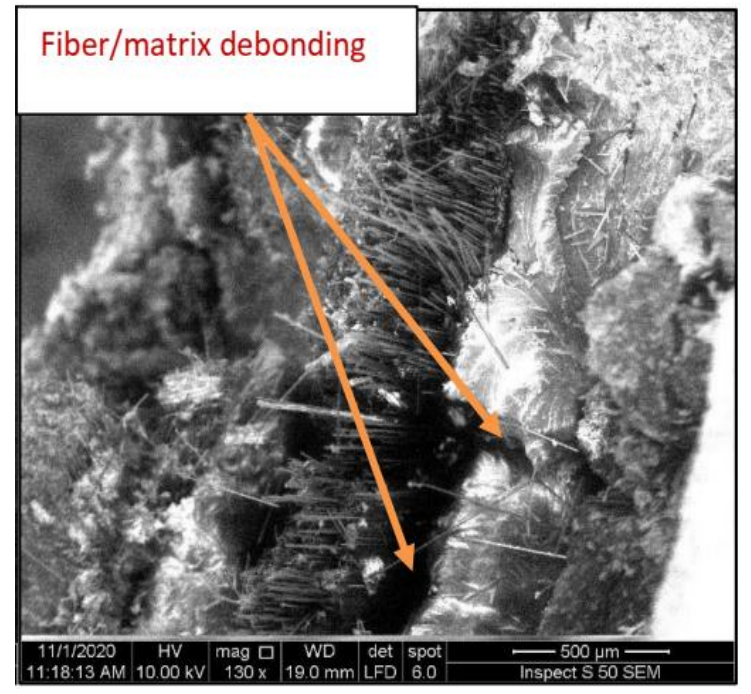

(h) $[\mathrm{EP}+\mathrm{C} / \mathrm{C} / \mathrm{C}+1 \%]$

Fig. 17. SEM images of fatigue failure for epoxy reinforced with three layer of carbon fiber and $(1,3$ and $5 \%$ wt.) of $\mathrm{TiO}_{2}$ nanoparticles.

2. Adding Titanium dioxide by $3 \%$ wt to the composite material with stacking sequence $(\mathrm{EP}+\mathrm{C} / \mathrm{C} / \mathrm{C})$ enhances its tensile modulus by $13.33 \%$ while it became $18.8 \%, 10.7 \%$ and 27.9 for the composite materials with stacking sequences (EP+GCG), (EP+CGC) and (EP+GGG) respectively.

3. Adding Titanium dioxide by $3 \%$ wt to the composite material with stacking sequence $(\mathrm{EP}+\mathrm{C} / \mathrm{C} / \mathrm{C})$ enhances its fatigue strength by $9 \%$ while it becomes $10 \%, 18 \%$ and $30 \%$ of the composite materials with stacking sequences $(\mathrm{EP}+\mathrm{CGC}), \quad(\mathrm{EP}+\mathrm{GCG}), \quad$ and $(\mathrm{EP}+\mathrm{GGG})$ respectively.

4. The hybrid nanocomposite material $\left(\mathrm{EP}+\mathrm{C} / \mathrm{C} / \mathrm{C}+3 \%\right.$ wt $\left.\mathrm{TiO}_{2}\right)$ shows the highest fatigue bending load (48 $\mathrm{MPa})$, whereas $\left(\mathrm{EP}+\mathrm{G} / \mathrm{G} / \mathrm{G}+3 \% \quad \mathrm{TiO}_{2}\right)$ sustain the lowest fatigue bending load (26 MPa).

5. The mathematical model built to study the fatigue behavior of hybrid nanocomposite materials was validated successfully by comparing the obtained results with that obtained from the experimental work with only $5 \%$ deviation in the results.

\section{RECOMMENDATIONS FOR FUTURE WORK}

1. Investigate the influence of varying volume fraction on the mechanical properties, and fatigue behavior, of such laminated composite materials.

2. Study the effect of particles addition by varying particle type (like carbon nano tube), particle size, and particle volume fraction.

3. Evaluate the fatigue damage of the hybrid nanocomposite materials under combined loading.

\section{REFERENCES}

1. Hollaway LC. A review of the present and future utilization of FRP composites in the civil infrastructure concerning their important in-service properties. Construction and Building Materials. 2010; 24(12).

2. Al-Turaihi A, Mehmanparast M, Brennan F. The influence of partial surface shot peening on fatigue crack growth behaviour of a high-strength ferritic steel. Fatigue and fracture of engineering materials and structures. 2018; 41(3): 663-674.

https://doi.org/10.1016/j.conbuildmat.2010.04.62

3. Grimmer CS, Dharan CKH. High-Cycle Fatigue Life Extension of Glass Fiber/Polymer Composite with Carbon Nanotubes. Journal of Wuhan University of Tech. Mater. SCI. ED. 2009: 167-173.

https://doi.org/10.1007/s11595-009-2167-4.

4. Shafi Ullah Khan, Arshad Munir, Rizwan Hussain, Jang-Kyo Kim. Fatigue damage behaviors of carbon fiber-reinforced epoxy composites containing nanoclay. Composites Science and Technology 70. 2010: 2077-2085. https://doi.org/10.1016/j.compscitech.2010.08.004

5. Deesy Pinto, Luis Bernardo, Ana Amaro, and Sergio Lopes. Mechanical properties of epoxy nanocomposites using titanium dioxide as reinforcement - A review. Construction and Building Materials. 2015;95:506-524.

https://doi.org/10.1016/j.conbuildmat.2015.07.124

6. Bernd Wetzel, Patrick Rosso, Frank Haupert, and Klaus Friedrich. Epoxy nanocomposites - fracture and toughening mechanisms. Engineering Fracture Mechanics. 2006; 73: 2375-2398.

https://doi.org/10.1016/j.engfracmech.2006.05.018

7. Ajaj EA, Jubier NJ, Majeed KJ. Fatigue behavior of Epoxy/ SiO2 Nanocomposites Reinforced with Eglass Fiber. International Journal of Application or Innovation in Engineering \& Management (IJAIEM). 2013; 2(9).

8. Shafi Ullah Khan, Arshad Munir, Rizwan Hussain, and Jang-Kyo Kim. Fatigue damage behaviors of carbon fiber-reinforced epoxy composites containing nanoclay. Composites Science and Technology. 2010; 70: 2077-2085.

https://doi.org/10.1016/j.compscitech.2010.08.004 
9. Borrego LP, Costa JDM, Ferreira JAM, Silva H. Fatigue behaviour of glass fibre reinforced epoxy composites enhanced with nanoparticles. Composites: Part B. 2014; 62: 65-72.

https://doi.org/10.1016/j.compositesb.2014.02.016 10. Md. Touhid Alam Ansari, Kalyan Kumar Singh, and Mohammad Sikandar Azam. Fatigue damage analysis of fiber-reinforced polymer composites-A review. Journal of Reinforced Plastics and Composites. 2018:37(9):636-654. https://doi.org/10.1177\%2F0731684418754713

11. Capela C, Oliveira SE, Ferreira AJM. Fatigue behavior of short carbon fiber reinforced epoxy composites. Compos. Part B Eng. 2019;164:191-197.

12. D'Amore A, Grassia L. Principal features of fatigue and residual strength of composite materials subjected to constant amplitude (CA) loading. Materials. 2019; 12: 2586. https://doi.org/10.1016/j.compositesb.2018.11.035

13. Lee CS, Kim HJ, Amanov A, Choo JH, Kim YK, Cho LS. Investigation on very high cycle fatigue of PA66-GF30 GFRP based on fiber orientation. Compos. Sci. Technol. 2019;180:94-100. https://doi.org/10.1016/j.compscitech.2019.05.021

14. Bondy M, Rodgers W, Altenhof W. Tensile fatigue characterization of polyamide 66/carbon fiber direct/in-line compounded long fiber thermoplastic composites. Compos. Part B Eng. 2019; 173. https://doi.org/10.1016/j.compositesb.2019.106984.

15. Mustafa Baqir Hunain, Salah N Alnomani and Qabas Razzaq. An investigation of tensile and thermal properties of epoxy polymer modified by activated carbon particle. IOP Conf. Series: Materials Science and Engineering. 2021; 1094. http://doi:10.1088/1757-899X/1094/1/012164.

16. Basim A Abass, Mustafa B Hunain, and Jaafar M A Khudair. Effects of titanium dioxide nanoparticles on the mechanical strength of epoxy hybrid composite materials reinforced with unidirectional carbon and glass fibers. IOP Conf. Series: Materials Science and Engineering. 2021; 1094. http://doi:10.1088/1757-899X/1094/1/012159.

17. Ali S. Al-Turaihi, Mustafa Baqir Hunain, Ahmed Fadhil Hamzah, Essam Zuheir Fadhel. Experimental and numerical investigation of fatigue behavior of chopped GFRP composite rod under rotating bending load. Journal of Mechanical Engineering Research and Developments. 2021; 44 (2): 324-335.

18. Mustafa Baqir Hunain, Salah N. Alnomani, Salwan H. Alhumairee. An investigation of the tensile strength of laminated polymer-matrix/carbon-fiber composites for different stacking sequence. International journal of mechanical engineering and technology. 2018; 9 (12): 606-614.

19. Product Datasheet.

http://dcp-int.com/iq/index.php?p=about.

20. Product Datasheet, Edition 26.09. 2012; Version no. 3. Pdf. https://che.sika.com,

21. Product Datasheet, Sichuan Weibo new material group co. Itd (china).http://www.wbo.cc/wap/en.

22. McCook NL, Boesl B, Burris DL, Sawyer WG. Epoxy, $\mathrm{ZnO}$, and PTFE nanocomposite: friction and wear optimization. Tribology Letters. 2006; 22(3). http://doi:10.1007/s11249-006-9089-5.

23. Al-Ajaj IA, Abd MM, Jaffer HI. Mechanical Properties of Micro and NanoTiO2/Epoxy Composites. International Journal of Mining, Metallurgy \& Mechanical Engineering. 2013; 1(2).
24. ASTM No. D 3039. Standard Test Tensile Properties of PMC Materials. 1996-2013 ASTM International. 2014; USA.

25. Salah N. Alnomani, Mustafa Baqir Hunain, Salwan $\mathrm{H}$. Alhumairee. Investigation of different failure theories for a lamina of carbon fiber/Epoxy matrix composite materials. Journal of Engineering Science and Technology. 2020; 15(2): 846-857.

26. Hodgkinson JM. Mechanical testing of advanced fiber composites. Wood Publishing Limited, Cambridge, England. 2006.

27. Avery 7305. Users' Instructions Manual. 1976.

28. Goldstein JI, Newbury DE, Echlin P, Joy DC, Roming AD, Lyman CE et al. Scanning electron microscopy and X-ray microanalysis. 2nd ed. New York: Plenum Press. 1992.

29. Varadharajan BR, Hung WNP, Sue HJ. Fatigue of Epoxy a Zirconium Phosphate Nanocomposites. Proceeding of the ASEE Gulph-Southwest Annual Conference Texas A\&M University-Corpus Christi. 2005.

30. Hussain J. Al-alkaw, Dhafir S. Al-Fattal,and Abduljabar H. Ali. Static tensile strength and fatigue behavior of polyester reinforced with the chopped strand mat (CSM) offiber glassat elevated temperature. Journal of Engineering and Development. 2013; 17(3):31-49.

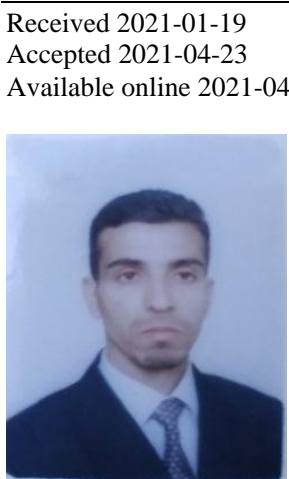

Mustafa Baqir HUNAIN Assistant Professor at the mechanical engineering of the University of Babylon, He got his B. Sc. degree in mechanical engineering in 2004, $\mathrm{He}$ received his $M$. Sc. in mechanical engineering (Applied Mechanics) in 2007, and his Ph.D. in mechanical engineering (Applied Mechanics) in 2014.

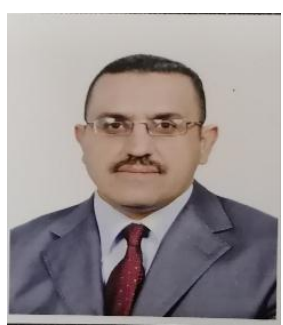

Basim A. ABASS - was born in Baghdad, Iraq in 1962. He received the B.Sc. degrees in Mechanical Engineering from the University of Baghdad, in 1984, M.Sc. in mechanical engineering (Applied mechanics) in 1989 from the University of Baghdad and the Ph.D. degree in mechanical engineering (Applied Mechanics) from the University of Baghdad in 1999. He was an assistant professor from 2009 till now at the university of Babylon, college of engineering, Mechanical engineering department.

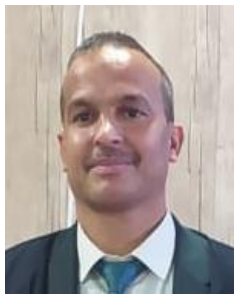

Jaafar Musa AKHUDAIR - M. Sc. student at the mechanical engineering (Applied mechanics) of the University of Babylon, $\mathrm{He}$ got his B. Sc. degree in mechanical engineering in 2002 from Tikrit University. 